\title{
Paddy field soil conservation: Indian historical practices
}

\author{
Deepak Bhattacharya \\ Head-Oddisi Research Laboratory, C/O Sri Radha Krishna, Bhubaneswar, India; Corresponding Author: oddisilab1@dataone.in
}

Received 28 January 2011; revised 5 July 2011; accepted 29 July 2011.

\begin{abstract}
India is an ancient land having high seasonal rain fall (4 months rain \& 8 months dry), has paddy cultivation. Becauses silt-sand separation; buoyant sand gets carried; silt agglutinates. Rill fluid dissolves agglutinated soil; vectors as silt $\rightarrow$ degradation. Indian farmer has unique agricultural field conservation; soil cum fertility maintenance/regeneration heritage; also use the stubble and cow dung (cellulose) as binder cum multi purpose in-field uses. Economic; ecologically safe; and not discussed earlier. Good tool for altruistic administrations.
\end{abstract}

Keywords: Stubble; Cow Dung; Paddy; Multi-Crops; Heavy Monsoon Rains; Soil Conservation

Abbreviation: Soil Moisture-SM; Rain Fall—RF; Outgoing Long Waves Radiation-OLR

\section{INTRODUCTION}

India an ancient nation having a continuous settled agriculture type of civilization for last few millennia is intently agricultural even to this day. During the same period numerous civilizations have risen and fallen. The Indian civilization continues. India is also known as Orient and rice (paddy: Oryza Sativa Linn) is the gift of the Orient. Paddy cultivation requires inundation which in turn requires copious rain. Much of India is also high land and has good gradient [1]. Has an annual average rain fall of the order ranging between $300 \mathrm{~mm}$ and 1500 $\mathrm{mm}[2]$. The annual gross rain fall and surface run off to the sea being of the order 400 billion $\mathrm{m}^{3}$ [3]. But copious rain is also associated with soil degradation and erosion. Indian (Hindus specially) are also world wide known for their ancient scientific knowledge base [4]. India's population has been leaping forward, and stress on land forms is mounting. Indian administration is often seen giving more priority to welfare of its Govt. employees than to the common man. Therefore, discussing time vetted, economically and ecologically safe practices is called for urgently. In this communication we examine how the native Indians have been conserving soil-bio mass. We report few unique practices and discuss the underlying scientific reasons.

\section{SOIL MOISTURE ASPECTS}

SM loss arises out of heat wave. India has 8 months of no rain period of which 4 months is noted for dry winds from the north-west (middle-east). In the rural, the natives of India do not use any term that can directly be associated with SM, which arises out of narrow agronomic consideration. They use the term murtika sanrakshana (soil conservation), which socio-culturally is a holistic usage. We again note Sri Balabhadra/Baldev/ Baldeo is the jaistha (senior most) - incarnation of Lord Siva Mahadeva (the supreme Hindu God) in his (former) farmer format, holding a ploughshare. Alike a farmer, his is a well built personage of impeccable character. So, the supreme Hindu God head in India is a farmer, indeed. In relation to our caption, we may aver that ancient India had given much importance to farming and to the farmers. In this segment we consider as to how the native Indian farmer has been coping with the principal underlying cause of 'SM loss' and how we have been inspired i.e. we discuss few tangible cum intangible heritage aspects. We then raise the question, what then has been the historical practice to retain soil moisture and to arrest soil erosion/field degradation? We note that, historically, the Indian and specially the east coast farmer (case of excess $\mathrm{RF}+$ prolonged dry + acute heat) has devised time tested methods to arrest soil erosion and top soil recharge. Herein the term 'farmer' denotes settlement based life (which in India is at the least 2 millennia old, recorded) and not podu (burn) nor jhum (shifting cultivation).

\section{OUT-DOOR OBSERVATION - RECORD}

Figure 1 is that of a small segment of a plot on dt.01- 


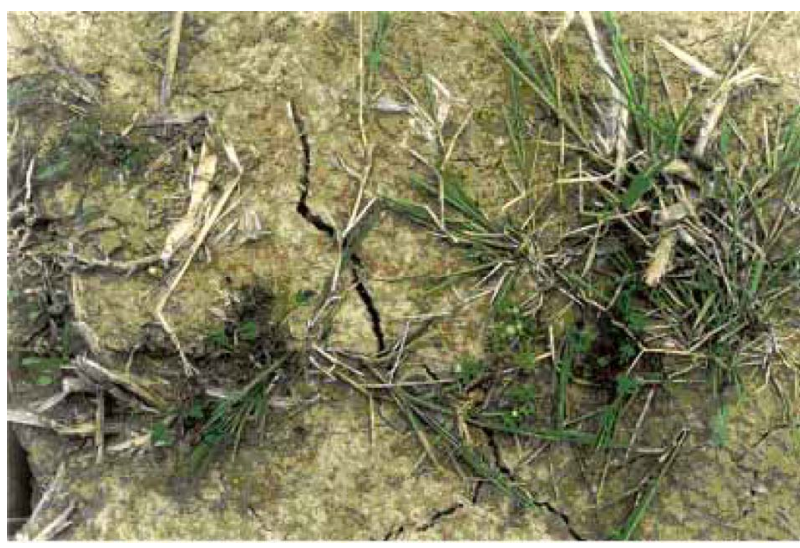

Figure 1. Stubble on field; post harvest period.

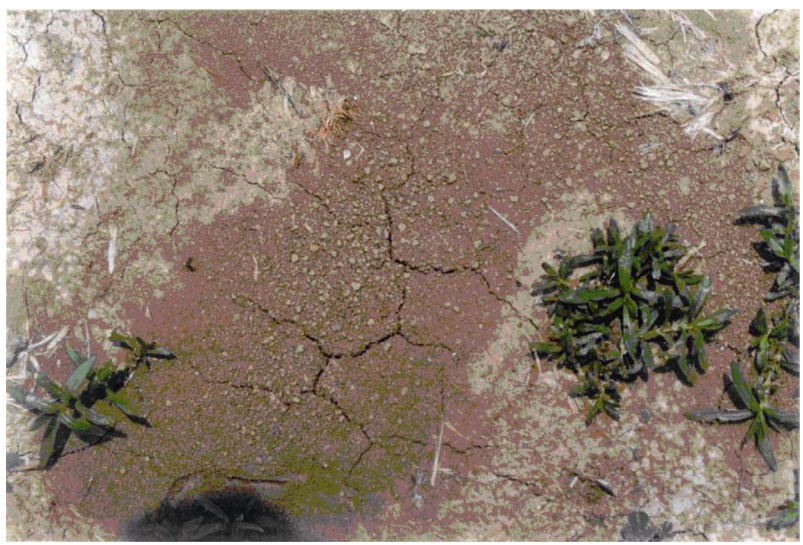

Figure 2. Stubble less field; post harvest period (nearby location of Figure 1).

03, 2007, well post removal of crop to khala (stock yard), location district Angul (central Odisa; onset of heat wave period). The field has good clay soil (chikita mati). Mono crop, rice cultivation has been practiced in this field for last few centuries (as far back as memory of the local native can go). The field has been left fallow, because of rain fed, subsistence type, and mono cropping practice (to be cultivated in next year rainy season). We can see the fresh off shoots from around the stubble. The soil looks moist, a fresh crack has evolved; the green shoots looks healthy. The cracks seem to avoid the location of the stubbles. Our Figure 2 is that of another plot in the neighbourhood (within a range of $500 \mathrm{mts}$ ) that has no stubble and has reddish type soil texture. Photographs are taken at the same period $(01-03,2007)$. We see that in the stubble less field even the low regions have more cracks (caking) than the upper regions. Our Figure 3 is that of the stubble filed (F-1 region) re-exposed during the Rajo festival period (mid June) i.e. pre next cultivation cycle [5], which is a non baroclinic period, whence invariably the coastal regions receive premonsoon showers. We can see that the stubble in the field is virtually

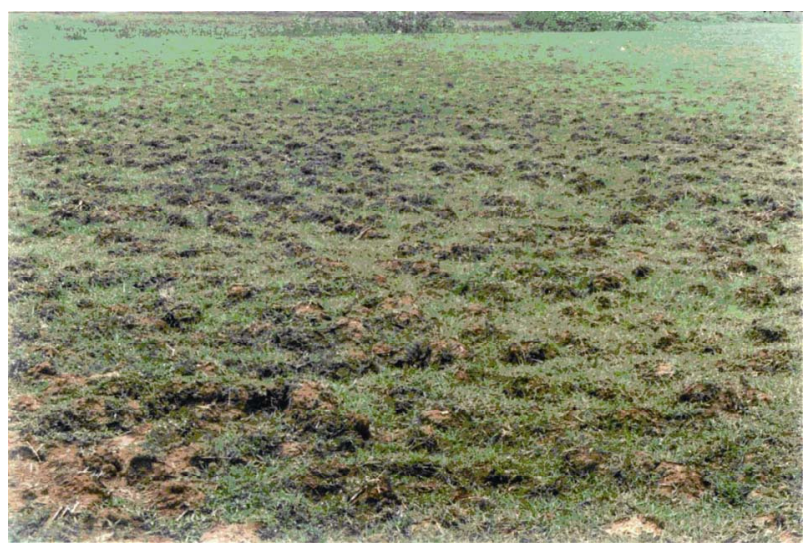

Figure 3. Stubble field as in Figure 1, re-exposed post field preparatory seasonal rains.

indiscernible (decomposed into soil). Instead a green carpet is noted with no sign of soil moisture stress or soil denudation or even surface erosion. During the same period the red soil, stubble less field (F-2) wore a desolate look with heightened caking, rills all over our erstwhile designate place (photo not included). Pre monsoon showers had inflicted remarkable surface level changes. We think that the contrast between Figures 2 and $\mathbf{3}$ could primarily be caused by the stubbles and the pre-monsoon showers have rejuvenated the green carpet although the soil had caked limitedly. K. G. Vernekar, et.al. [6] have indicated that SM and vegetation effect atmospheric boundary layer and land surface processes. We relate with evolution of refractile ecology and socio-economic stress. In other words this results in turbulence and becauses rain.

We raise the question, why should the soil crack? And cake (disassociate from the ground)? Surface soil moisture is the water that is in the upper $10 \mathrm{~cm}$ of the soil, whereas root zone soil moisture is the water that is available to plants, which is generally considered to be $200 \mathrm{~cm}$ downwards from the top surface of the soil. SM is expressed in ' $\%$ ', wherein $75 \%-100 \%$ means 'wet muddy' and forms ball when clasped by (bare) palm. We also found that as evapotranspiration proceeds from the surface due to top heating from astronomical source, the soil looses mass, shrinks in volume. Loss of fluid makes the soil less elastic. Yet, no work has been done on the surface. However there has been loss of volume in terms of fluid loss via the top surface which is (also) work done - beneath the surface (due capillary motion). Drying, i.e. loss of volume proceeds from the top. Physical property between the surface (hard) and the inner soil (soft) take a paradigm shift. The dried surface area has to remain constant (or else it is not hard). Moisture stratification happens. Soil is permeable, due osmosis moisture must flow out. The contrast of physical property (vol- 
ume: mass) between the outer and the inner layers of the soil leads to infractions (internal fractions). In fact the infractions are 'shear cracks' due to opposing longitudinal forces. The point of least resistance is the point of shearing. But, soil is homogenous. Therefore, internal binders act as resistors. In order to retain surface architecture (which was formed when soil had higher plasticity) the (dry) surface has to crack and readjust to the new volume: mass conditions of the underlying strata. Subsequently, it is through these cracks moisture from inner layers start escaping into the atmosphere (which has a lower relative humidity). Soil masses around which fine cracks have developed experiences heightened SM loss from enhancing depths. Differential contraction and variable shrinking from all sides (which) also assists in irregular cracking, widening, gets isolated as a 'cake'. The cake undergoes moisture loss from all around its edges and along the inner line of disassociation as compared to the top-exposed mid regions; this creates the (unique) pan shaped cake. Decrease in surface area (concave architecture) occurs to reduce the area that is incident to astronomical heating. It is a preferred (natural) thermodynamic architecture. This in turn acts as a 'object for frying' and finally disassociates from the lower strata with SM loss $>80 \%$. Powderisation process and wind's erosive action then start registering. Sand silt separation sets in. Process desertification has been initiated.

In contrast to such mechanics, wherever available, the stubble roots hold soil in clumps, acts as capillary pathways for soil moisture translocation. Therefore, superficial roots act as 'resistors, while the stubble acts as aerial(s) for evapo-transpiration and also provide limited shade to the soil. The stubble being porous weatherized hay acts as an insulator of heat, with a hollowed centre made of long fiber cellulose. It acts as antennas (projecting into the air mass) and traps ground skimming cum escaping moisture from the vicinity, and re-translocates back into the soil by reverse capillary mechanism towards the parched soil, post dawn every day $\rightarrow$ few hours into the pre-noon. Further, during dusk to dawn period, nocturnally condensation occurs on the aerial stubble. Such moisture is also reverse translocated back into the root base soil. Overtime, the entire blocks of the stubble cum roots turn into soil, pre next field preparation. When admixed in soil, the stubble also act as 'moisture retainers', apart from its initial 'binder' role. Therefore, stubble less plain surface (although it offers least surface area) leads to more cracking, caking, rill formation even during pre-monsoon showers and extensive top soil loss. We also note that feet trampled (pug marked) semi-dried undulated surface (Figure 3) offer variable angles to the radiant Sun, create micro shadow areas and also down regulate OLR. Therefore wet land, moist land and standing crop fields respectively give out less OLR, create scope for lot much work done in the land-atmosphere couple; impede process barocilinic.

\section{INDOOR EXPERIMENTS}

Two experiments were done of which one was to verify the heritage practices of the Indian farmer. An segmented tray was taken. Two sample of identical volume of soil was collected from the field as in Figure 3. Samples of neat soil were made wet and poured into the segment marked ' $A$ ' of the tray. Into another neat soil of identical volume was admixed 5\% hay and 5\% dry cow dung by volume and stirred to uniformity with identical amount of water and poured into the segment marked ' $C$ ' of the tray ( to viewer's right Figure 4). The tray was left to dry in hot summer of May (Bhubaneswar: $+20.5 \%$ $\left.+85.82^{\circ}\right)$. After 7 days, the photograph was exposed. We can see that segment ' $\mathrm{C}$ ' which contains $5 \%$ hay and $5 \%$ dry cow dung (as alike the usage by the Indian farmer) has developed less cracks, although both the samples are dried to a moisture content of less than $5 \%$. Therefore, the historical practice of adding cow dung, burnt plant matter (variously treated cellulose) and retaining the stubble is deemed applied science.

\section{CO-RELATIONING OF ON-FIELD OBSERVATIONS}

On field study, it is noted that the agriculture fields seem to retain loam and finer silt comes to the top when

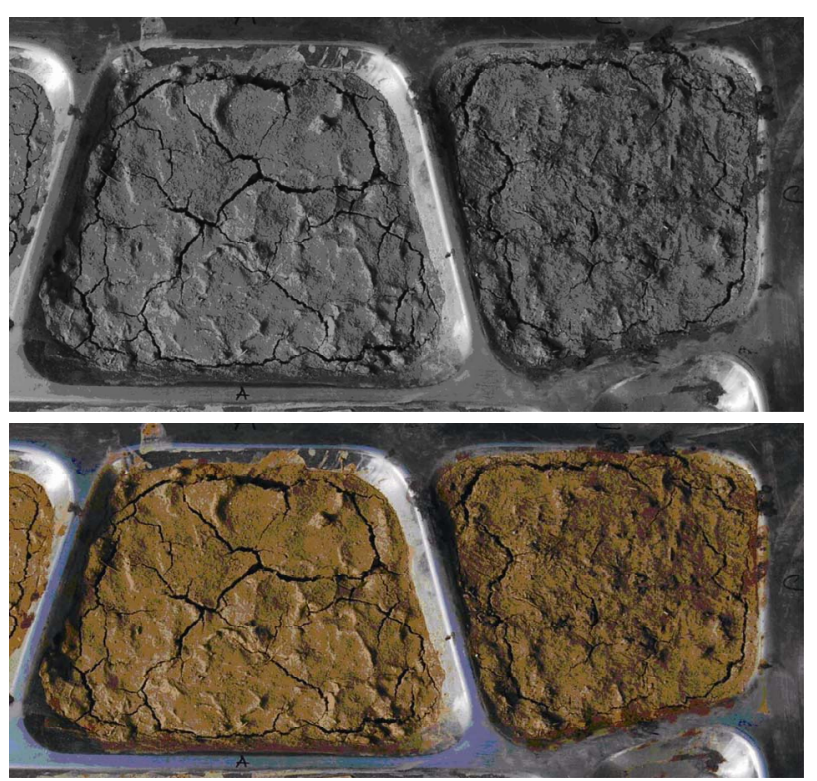

Figure 4. In-lab demonstration of soil binding effect of dried stubble \& cow dung (cellulose). 
wet. The sand seem to flow away towards the peripheries. We raise a question why? An experiment was conducted in the field. A block of soil was dug out from the field as in Figure 3 and deposited on the surface (Figure 5). It was allowed to get exposed to natural weathering process for only 2 weeks. We can see in Figure 5 that sand has come to the top. Figure 6 is that of post 6 months (spring and pre-monsoon shower exposed). We can see sand has virtually been washed/removed. Loam has formed as a pack and has yet not experienced any denudation/scouring/rill formation. Figure 7 is post 14 months, we can see that loam is appearing as very sticky and has experienced extensive scouring and rill formation. Hence we may say that sand (silica particulates) being more buoyant due to less specific gravity than silt particulates (which are finer), get to top when fluid is added to solid (soil). Loam adsorbs water and then develops a binding property, while silica does not. So, fluid action is the cause. Moreover, fluid thrust on larger surfaces (herein sand particles) is more linear (Pascal effect) while on smaller surfaces (herein loam) it is more non linear (non Newtonian effect). However, sand is very important as a constituent as it also (limitedly) acts as a binder and thermal regulator (silica property). In the stubble field however, the sand that is expressed to the surface during inter-crop periods eventually fall and sink into the cracks/crevasse and get re-assimilated into the soil matrix. There is a no loss. It is a loop. Hence allowing a inter-crop period is good for soil conservation! This is history of soil conservation applied science.

\section{DISCUSSION}

Addition of water (RF) makes soil buoyant (gain volume). Constituent sand (silica) has lower specific gravity; greater surface area becomes relatively more buoyant and is pneumatically raised to the upper regions (quenching stage dependant). Whereas, constituent silt (the ma-

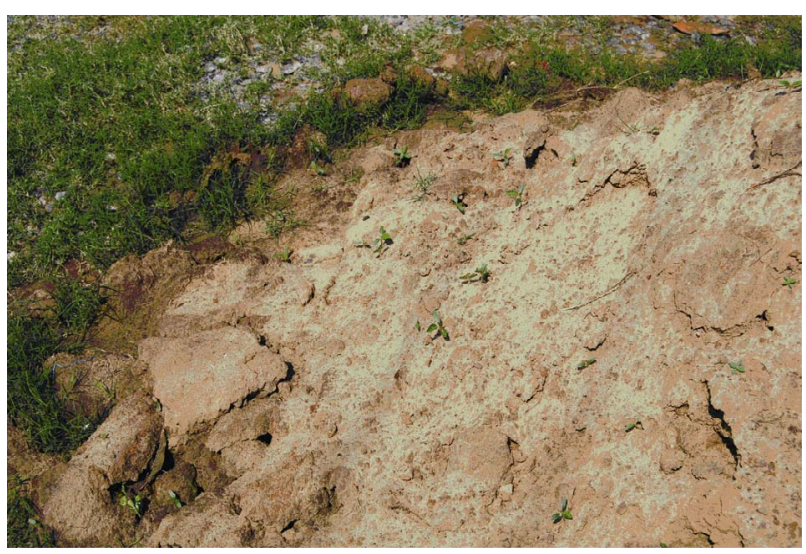

Figure 5. Sand particulates come to the surface and silt clumps and sinks in exposed soil (non rain).

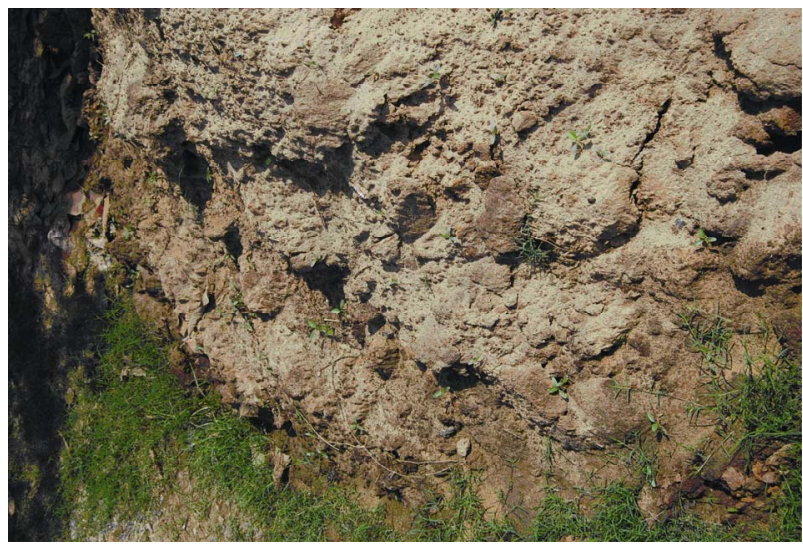

Figure 6. Sand particulates are washed away and silt clumps (as in Figure 5) and sinks in soil exposed to initial rainy season.

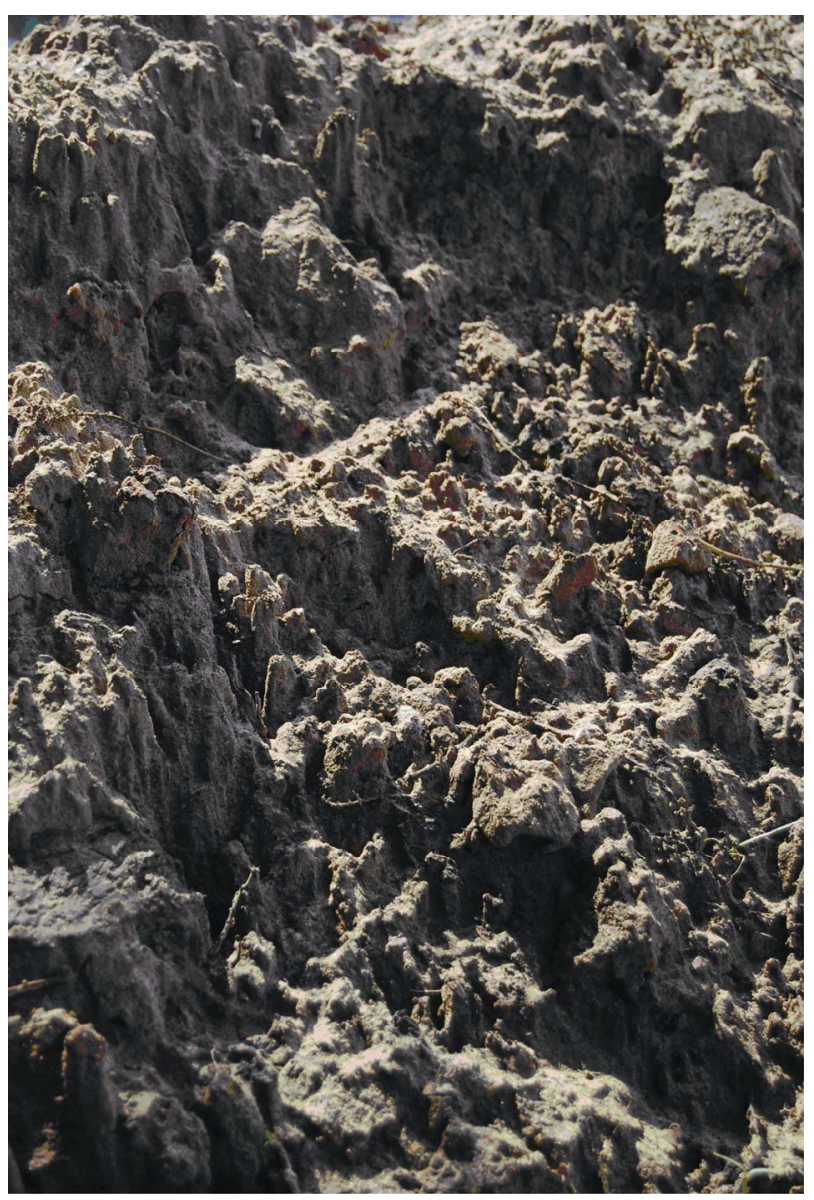

Figure 7. Silt clumps (as in Figure 5); appearing very sticky, has experienced extensive scouring and rill formation post expouser to full rainy season (Indian monsoon).

jor component by weight \& also greater bulk density) sinks deeper. This is mechanical. Separation is potentiated and occurs if there be alternating wet-dry spells. Buoyant sand gets carried easily and earlier (than silt) 
during initial rain. Thereafter, the kinetic energy component of a rain drop (on ground hit) gets fractionated efficiently (due greater cross section of the sand particulate that populates the upper regions) and dissipates into the crystalline structure(s); radiating upwards (towards lower bulk density). Whereas, the cohesive mass of the silt segment develops a shock wave type behavior, radiating downwards (towards higher density) leading to compaction. All this are due to the imparted energy. Tropo-Equatorial RF is marked by large droplets; freefalling from higher altitudes (convective clouds). Again, in cultivable soils, acids have affinity for the silt component, and alkalis have for the silica (inert). Injection of adequate neutral fluid (viz. RF) generates a surfactant effect. Water washes additionally. All this happen pre rill formation.

Silt also agglutinates and tends to clump. Rain water being Newtonian fluid when energized, exhibits centrifugal property until dissipation of the kinetic component. This additionally assists separation, mechanically. Post rain, low energy surface flow only dissolves and carries silt. In agitated state the carrying capacity of Newtonian fluids rises exponentially. Rill forms due to significant amount of unhindered flowing fluid (period $\&$ volume of surface flow). Rill fluid is in hyper agitated state. It is stream flow having significant velocity (high energy/Reynolds). Scours and dissolves the agglutinated material and vectors the (silt). This results in land form degradation. Stubble robustly down-regulates all the stages, even rill formation. Stubble is a formidable barrier. Stubble field is the secret behind the historically well conserved soils.

The eastern coastal district of Ganjam in Odisa, India has a decadal annual average RF of only $800 \mathrm{~mm}$ and yet is the granary of that province. It is relevant to relate that paddy requires on an average $750 \mathrm{~mm}$ of RF. Although much of Ganjam's domain is precipice and highland (with bare sustenance amount of RF) such bounty production (granary aspect) is possible only because the farmer also puts leafs and whole hay, burnt organic matter as well. Carbon from burnt organic matter we know traps nitrogen, while wood carbon has a surface area of the order $1000-2000 \mathrm{mt}^{2} / \mathrm{gm}$, also adsorbs moisture and helps in retaining SM that assists soil binding. Hence, soil cracking and moisture loss is down-regulated due the 'binder effect' of the stubble's roots cum cow dung $\&$ ash (which is loaded with digested cellulose). This is an example of such soil conservation sciences in applied form.

Therefore, organic long fiber binders can thwart SM loss and consequent top soil loss, etc. Excessive cracking of stubble field is a conclusive early (warning) sign of 'heat wave' and impending 'Sun stroke conditions'. The occidental farmer is not known to have such practice (wherever such practices are not noted desertification mechanics have evolved). Our inspiration for this experiment came by observing the field preparation inputs by the Indian farmer in general and via personal communication from farmer's guilds collected ranging over a decade.

\section{ACKNOWLEDGEMENTS}

Heavy RF and even alternating wet-dry spells, inflicts sand-silt separation leading to soil \& surface degradation, if the top soil be bare. The mechanics proceeds as poly modal (not as a cascade). Adding cow dung, burnt plant matter (variously treated cellulose; carbon particulates) and retaining the stubble acts as anti-dote. The administration can do precious enough by monitoring soil cracking i.e., SM loss over extensive region (earliest signature). India has a good data bank in agro-met domains. The data should be opened to the public (IMD and GOI data are not available to the common man, because the administration considers the common man as suspect and treats alike alien citizen. Moreover, almost every thing in India is by the Govt., of the Govt. and for the Govt.). The nation can then pre-calculate with near precision about likely period, and intensity of any impending 'Heat wave' conditions in relation to time and place, and its impact on flora, fauna and anthropomorphs (homeotherms). Heat wave effect on homeotherms is preceded by noticeable effect on poikilotherms such as lizards; snakes and other non climber reptiles often coming on-ground or trying to climb trees; absence of butterflies; juvenile sized leafs falling off from trees (off season patjhar), wide spread viral attacks on domesticated animals and pets, many similar signs (again a series, pre human fatality).

\section{REFERENCES}

[1] Panigrahi, D.K., Mohanty, P.K., Acharya, M. and Senapati, P.C. (2010) Optimal utilisation of natural resources for agricultural sustainability in rain fed hill plateaus of odisa. Agricultural Water Management, 97, 1006-1016. doi:10.1016/j.agwat.2010.02.005

[2] India Meteorology Department (1990) 30 year data book (1950-1980). Vth Edition, Government of India, New Delhi.

[3] Planning Commission (2002) Report of the committee on India vision 2020. Planning Commission, Government of India, New Delhi.

[4] Bhattacharya, D. (2010) Indian ancient sciences. Lap Lambert, Germany.

[5] Rajo festival is celebrated in Odisa very intently. It is a 3 day deemed (cultural) menstruation period for mother Earth. No earth related activity are done. Farm implements are put on worship. Ladies do not cook, take to the 
swing. Outside it is cloudy, sultry and breezeless. Swing helps in evapotranspiration $\rightarrow$ cooling $\rightarrow$ feel comfort factor.

[6] Vernekar, K.G., Sinha, S., Sadani, L.K., Sivaramakrishnan, S., Parasnis, S.S., Brij, M., Dharmaraj, S., Patil,
M.N., Pillai J.S., Murthy, B.S., Debaje, B.S. and Bhagavatsingh, A., (2000) An overview of laspex. Bundary-Layer Meteorol, 106, 561-572.

doi:10.1023/A:1021283503661 